\title{
Application of Game Theory in Mathematical Comprehensive Quality Training System
}

\author{
Feng-Jun Yan \\ Department of Foundation, Xian Siyuan University, Xian 710038 , China
}

Keywords: Game Theory; Mathematical Comprehensive Quality Training; Training System

\begin{abstract}
For talents cultivation, the improvement of the comprehensive quality of mathematics is very important. Only the scientific mathematical thinking logic can help to stand out from the crowd and become a full-scale development talent for the society. With the continuous development of the times, the concept of game theory has been proposed, which has created an important influence on the development of the overall quality of mathematics. There are drawbacks in the traditional comprehensive quality training method while the Nash equilibrium in game theory can make up for the inadequacies of traditional training systems and optimize the ratio of theoretical and practical courses. This article will specifically discuss the application of game theory in mathematics comprehensive quality training system, hoping to provide some references for related people.
\end{abstract}

\section{Introduction}

The cultivation of mathematical comprehensive qualities is the only way for individual talents. Whether dealing with life problems or dealing with social practices, mathematics comprehensive qualities are indispensable. The analysis on mathematical comprehensive quality training can help to find that both theoretical training and practical training are indispensable. Theoretical training is the forerunner of practice training, and practice training is the basis for theoretical training. Only by adjusting the ratio of theoretical training and practical training, and optimizing the content of theoretical training and practical training, can we improve individual's mathematical reasoning ability. Traditional mathematical comprehensive quality training system is conducted based on theoretical education, which to a large extent suppressed the students' enthusiasm for learning. Therefore, we have to create equilibrium for both theoretical and practical courses to analyze mathematical comprehensive quality training from the perspective of game theory.

\section{Introduction of Game Theory}

Connotation. Game theory is "the study of mathematical models of conflict and cooperation between intelligent rational decision-makers". It can be derived from applied mathematics and possess similarities. It is worth noting that the game theory is more comprehensive and the applicators must possess a certain knowledge of operational planning in addition to mastering modern mathematics knowledge. Game theory has the following application conditions: First, individuals need to be in a specific space environment and be bound and constrained by the outside world $^{[1]}$. Second, individuals can choose information according to their preferences, and harvest the results of the two information choices. Third, individuals can use two competing methods: the first is independent competition and the second is cooperative competition and the goal is to maximize its own revenue. Finally, individuals need to make a scientific distribution of their interests and strive to achieve personal and social values. In general, when applying game theory, the subject has built a scientific game model. The game model involves many objects. These objects can use differentiated game strategies. Each object represents different interests and the game order is not the same. The ultimate goal of the game is to gain, that is, under the condition of limited rationality, the ultimate benefit will be obtained by applying the game strategy.

Game Theory and Mathematics Education. Education in our country continues to develop, and the whole society has put forward higher requirement for the mathematics field. In order to 
promote the reform of mathematics teaching, China has adjusted the traditional education model and made mathematics education develop in the direction of modernization. Compared with foreign mathematics education, the level of mathematics education in China is relatively high, and the overall quality of the country's mathematics is also relatively high. From the perspective of mathematics teaching, our country also adopts a class teaching model. The professional competence of mathematics teachers is related to the quality and efficiency of mathematics teaching. The higher the professional level of mathematics teachers have, the higher the quality and efficiency of mathematics teaching will be. In class, teachers need to teach students basic knowledge, introduce learning methods, and so on. Students can ask questions and ask teachers to answer for themselves. Mathematics education is based on the mathematical syllabus, using mathematics textbooks as a basis and carry out teaching in classrooms with students and teachers as participants. The study of students and teaching of teachers are not one-way, and they should be interacted and create mutual benefits.

Mathematics education emphasizes the relationship between teaching and learning, and game theory studies the relationship among subjects. Game theory aims at achieving the optimal solution, and mathematics education takes student development as an important goal. From this perspective, there is a relationship between game theory and mathematics education. In the mathematics classroom, teachers and students are also playing a game. How to achieve personal growth and accomplish teaching goals has become the biggest problem for teachers and students. From the perspective of game theory, mathematics teachers and students need to examine each others' tactics in the teaching process and reach the balance between the two sides as far as possible ${ }^{[2]}$. Only by achieving a win-win result can the effectiveness of mathematics education be brought into play, and the sustainable development of mathematics education in China can be promoted.

\section{The Insufficiency of Developing Mathematical Comprehensive Quality from the Perspective of Game Theory}

Teaching Low Effectiveness. For a long period of time, China has adopted exam-oriented education which is considered as backward teaching methods. This has greatly suppressed students' interest in learning and adversely affected the classroom. Teachers are the mentors of students and play an important role in the development of students. Only by giving play to the teachers' guiding role can students' initiative be brought into play. It is worth noting that many teachers are still constrained by traditional teaching methods and use oral instruction to teach students theoretical indoctrination. Due to the lack of new teaching methods, mathematics classes are boring, and students cannot consciously enter into the teaching situations created by teachers and digest and understand mathematical knowledge.

Vague education subject. The mathematics discipline has comprehensive characteristics. Teachers must not only explain theoretical knowledge to students, but also guide students to apply mathematics knowledge to practice mathematics. In order to realize the combination of theory and practice, some teachers have explored new teaching methods. The continuous development of China's network information technology and its closer integration with the education industry has spawned modern education technology. Many teachers apply modern education technology in the classroom to present students with pictures, audio, and video, which confuse students with teaching priorities. Mathematics teaching should focus on concept teaching, rule teaching, and exercise teaching. If teachers focus too much on the teaching style, mathematics teaching will be trees without roots.

Role swap failure. In the context of the reform of the teaching system, teachers need to swap roles with students. In the traditional teaching classroom, teachers occupy a dominant position while both teaching and learning are one-way. Mathematics teaching emphasizes teaching and learning, students should absorb the knowledge taught by teachers, and teachers should also accept feedback from students. Many teachers neglected the importance of two-way interaction in teaching, making it difficult to improve teaching efficiency. The continuous development of our country's education cause has made students' principal position more prominent. Some teachers don't 
highlight the students' main status and swapped roles with students, leading to adverse effects on mathematics teaching.

\section{The Application of Game Theory in Developing Mathematical Comprehensive Quality}

Relieve Conflicts. In mathematics teaching, both teachers and students occupy very important positions. Teachers are the mentors of students and undertake the task of dispelling misunderstandings for students. The greatest responsibility of teachers is to promote the development of students and realize the goal of talent cultivation in primary school. Students are the ones who absorb knowledge and shoulder the important task of the great rejuvenation of the Chinese nation. The biggest responsibility of the students is to complete their studies and achieve personal and social values. From the perspective of game theory, the goal for teachers to carry out teaching should not be only to meet their needs of food and clothing but also spiritual needs ${ }^{[3]}$. At the same time, students should not only pursue mathematical knowledge to survive but also to develop themselves to contribute to the society. Both teachers and students have their own value and pursuits, which increases the possibility of conflict between the two. In order to ease the conflict between the two sides, it is necessary to analyze the causes of the conflict and promote mutual reconciliation.

For example, in the development of mathematics comprehensive quality, teachers can creatively use the game matrix to form a corresponding game model. The teacher-student game theory is based on whether or not the students listen to the lesson. Therefore, the game matrix should involve two parts: the first part is the student's lecture response, and the second is the teaching. There are two attitudes towards the students attending classes: The first is a serious attitude, and the second is not a serious attitude. Teacher teaching has three results: The first is poor teaching, the second is general teaching results, and the third is good teaching results. After building the game model, the relationship between teachers and students can be judged ${ }^{[4]}$. Both teachers and students are important parts of the game relationship. When there are conflicts between students and teachers, there are three strategies for teachers to choose. The first is good teaching; the second is general teaching; the third is poor teaching; Students have two strategies to choose from. The first is to listen carefully and the second is not to listen carefully. According to the results of the game, it can be found that the teaching process is not completely transparent and the teaching psychology cannot be grasped. In order to improve the quality of the overall quality of mathematics training, teachers need to communicate with students, use the best teaching methods, require students to listen carefully, so as to gain the best teaching results.

Create A Good Atmosphere. The teaching atmosphere has an important influence on students and teachers. Under the influence of a good atmosphere, students can more actively participate in mathematics classes and absorb the mathematical knowledge taught by teachers. Therefore, teachers should adopt modern educational technology to create a good teaching environment and a harmonious teaching atmosphere so as to carry out in-depth communication with students.

For example, in the teaching process, teachers should seek students' opinions on mathematics teaching and see what part of mathematics students most want to know. In order to verify the student's absorption of knowledge, teachers should adopt problem-based teaching methods to prompt problems and actively interact with students. After the classroom teaching is basically completed, teacher needs to arrange the exercises so that the students can practice. Exercise questions can test whether the student masters the mathematics theory. If the student can solve the problem independently, the teacher should start explaining the next content. If the students cannot apply the theory to practice, the teacher should also deepen the students' understanding of the knowledge of the course and promote the discussion and cooperation among students.

Adopt Language Pitch. Language pitch plays an important role in mathematics teaching. When students make mistakes, teachers should selectively use the language to direct them to the right track. For example, many students have problems with the memory of mathematical formulas. There are a glittering array of mathematical formulas, and similar mathematical formulas are innumerable. In order to reduce the occurrence of mistakes, teachers can use the "formula 
protection method" to formulate measures that violate the formula protection law, such as transcribing wrong questions and doing the same 10 types of questions as the wrong ones, in order to deepen students' understanding of mathematics knowledge.

\section{References}

[1] Lu Zhou,Xin Sun,Chunhua Su,Zhe Liu,Kim-Kwang Raymond Choo. Game theoretic security of quantum bit commitment. Information Sciences, 2018.

[2] Samson Lasaulce. A Very Short Tour of Game Theory. Elsevier Inc.:2011-06-15.

[3] Ben D. Mor. The Heuristic Use of Game Theory: Insights for Conflict Resolution. World Political Science Review,2011,3(2).

[4] Akira Okada. The History and Present State of Game Theory. The History of Economic Thought,2007,49(1). 